\title{
Ensuring the skills of tomorrow's psychiatrists
}

\author{
My plans as Dean
}

\author{
Cornelius Katona
}

I have now been Dean of the College for just over two months. The learning curve is still very steep, and I look forward to my own continuing professional development in the role over the next few years! These are exciting times in medical education, with major changes taking place at all levels in the training of doctors. I hope that I can contribute positively towards making these changes educationally meaningful - and enjoyable - for those of us lucky enough to be working in psychiatry.

I believe that we need to have clear educational goals and principles underpinning all our educational activities, and that we must promote a culture of active 'lifelong learning'. This will result in enhanced patient care, better research and improved morale. I am currently working on a new educational strategy document which will set out these principles and a set of specific goals, together with an action plan for achieving them. I hope that this educational strategy will provide a firm basis from which to work, and one that will enable the College to consolidate its position as a centre of educational excellence while also sharing skills and experiences with teachers from other disciplines and other countries. In this editorial I will summarise what I think such an educational strategy must contain if we are to ensure that not only tomorrow's new psychiatrists, but also those of us continuing to practise, achieve and maintain our psychiatric skills.

Within the spirit of 'lifelong learning' we must address the rapidly developing 'evidence-base' that makes the challenge of getting, and then keeping, up-to-date formidable indeed. There is also an increasing expectation that training and Continuing Professional Development (CPD) should emphasise skills and positive attitudes rather than pure knowledge. 'Calmanisation' and harmonisation with Europe have both increased the pressure for specialist training to be completed within a relatively short time. To continue to add to the training burden of doctors without lengthening the time of training could lead to a reduction in quality. We have to recognise that not all areas of psychiatry, however important they might be, necessarily constitute a part of core training. I think it is crucial to identify and continually update the core components of psychiatric training at all levels.

We must continue working to ensure equity among all trainees, irrespective of race, gender, or the need to work part-time. For example, trainees with family commitments and those involved in basic science research will need individualised training programmes to enable them to achieve the same level of knowledge and skills as their full-time counterparts. We must also recognise that some trainees, and some consultants, will run into difficulties. Supporting them while maintaining safe service delivery is an educational as well as a moral obligation.

\section{Psychiatry for undergraduates}

Until recently, the College has had little involvement in undergraduate teaching. Undergraduate psychiatry experience can help ensure that doctors destined to work in primary care or other hospital specialities have skills to deal with their patients' psychiatric problems. It also provides an opportunity to recruit good trainees into psychiatry. The College is in a strong position, through the University Psychiatry Committee and through links with the Association of University Teachers of Psychiatry, to provide advice on what should be included in a core undergraduate psychiatric syllabus, on effective teaching and appraisal methods, and on how to negotiate with other interests within medical schools that might wish to 'squeeze' the psychiatric component of a medical school's curriculum. We could also help individual medical schools not to reinvent too many wheels by using the College Web site to display and share undergraduate teaching expertise.

The group of doctors working as pre-registration house officers (PRHOs) may also be a potential source of new recruits into psychiatry. 
PRHO training in psychiatry has been available in Sheffield for many years, but there have been few such opportunities elsewhere. In my view, the College could and should encourage the development of such schemes and help define appropriate training at PRHO level.

\section{Basic specialist training}

The quality of basic training has improved considerably in recent years. The network of College tutors and the rigorous and standardised accreditation process for senior house officer (SHO) schemes have been crucial in achieving this. There remains considerable scope for improvement in the assessment of trainees. The Log Books recently introduced could help a great deal in monitoring the acquisition of relevant skills. Local MRCPsych courses vary widely in quality - review of their educational goals and content should be an important part of the accreditation process for SHO schemes. The weekly supervision between educational supervisor and trainee is the best opportunity for monitoring the progress of individual trainees. All educational supervisors will need appropriate training in teaching and assessment skills - as has long been required by medical schools for teachers of undergraduates. The College will need to develop its own teaching skills courses for psychiatrists.

I am delighted that the College is undertaking an overall review of the MRCPsych examination. Any resultant changes must be justified in educational terms and should be planned with adequate forewarning of trainees and teachers. It is vital that, through the Collegiate Trainees' Committee (CTC) trainees be involved in the review process. I personally would like to see consideration given to the use of modern assessment methods such as Objective Structured Clinical Examinations (OSCEs), and to the introduction of an audit/quality project complementary to the new critical appraisal paper. More generally, the exam must have a clear syllabus with assessable educational objectives. Review and systematisation of the syllabus would also provide an opportunity for the College to be involved in producing comprehensive multimedia teaching aids for trainees linked to the syllabus and continuously updateable.

\section{Higher specialist training}

We have made considerable progress in defining the educational objectives for higher specialist training in each of the psychiatric sub-special- ities. We are also learning to work in partnership with the Regional Deaneries and with the Specialist Training Authority in monitoring higher (and indeed basic) training. In my view, we need to make higher specialist training increasingly skills-oriented. In particular we need to decide what core exit skills those in higher specialist training need in order to function competently as consultants, and how those skills should be assessed. We must also remember that the challenge of moving from the relative protection of specialist registrar posts into the consultant firing line is considerable. With this in mind, appropriate exit skill requirements might include: evidence of being able to work effectively in a multi-disciplinary team; leadership skills; management and supervisory experience; and teaching experience.

\section{Continuing Professional Development}

The transition from training to career grade is far from being the end of an educational process - it is merely a move from one stage of lifelong learning to another. CPD is the framework within which the College helps maintain the skills of today's and tomorrow's psychiatrists. It should complement practice-based learning and help all of us working in consultant and other non-training grades not only to keep up-to-date but also to remain interested in and excited by our work, and to protect ourselves from burn-out. The need for us all to keep our knowledge base, skills and working practises up-to-date is highlighted by recent moves towards specialist reaccreditation which should. I think, be seen as an opportunity rather than a threat! Like training. CPD should be achievable and enjoyable. We must develop a system that is sensitive to individual needs and aspirations, has clear educational objectives and is preplanned rather than driven by availability alone. CPD also provides part of a framework to support psychiatrists with problems.

I think that all career psychiatrists should be involved in CPD and am delighted that the CTC and the CPD committee have both recommended that CPD be mandatory for educational supervisors.

\section{Dean's surgery}

The success of what I am proposing depends entirely on the support of the membership as a whole. I hope that this will be made easier by my being available to discuss educational issues and concerns with any of you who want to talk to me. I am setting up a regular Dean's surgery to take 
place on alternate Friday afternoons from 4.00 to $5.30 \mathrm{pm}$. In these surgeries, I will be available by telephone or in person to any trainee, affiliate. member or fellow wishing to talk to me. To make an appointment, please contact my secretary, Ms Lena Hartley, on extension 139 at the College, telephone 01712352351 or by e-mail (lhartley @rcpsych.ac.uk).

Cornelius Katona, Dean, Royal College of Psychiatrists, 17 Belgrave Square, London SW1X 8PG

\section{Occasional Paper 43 Higher Specialist Training Handbook}

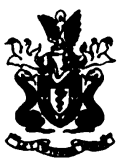

This is the eighth edition of the Higher Training Handbook and the first to be produced under the newly constituted Higher Specialist Training Committee; the previous seven editions having been issued under the name of the Joint Committee on Higher Psychiatric Training. This edition brings together the requirements for approval of schemes with the criteria for award of certificates of completion of specialist training. It also outlines the type of training for which ad hominem approval may be sought, explains how assessment procedures should function and recommends how training schemes should be organised. Finally, brief details are given on the application procedure for award of a certificate of completion of specialist training.

OP43, £7.50, March 1998

Available from Book Sales, Royal College of Psychiatrists 17 Belgrave Square, London SWIX 8PG

Tel +44 (0) 1712352351 (extension 146), Fax +44 (0) 1712451231 The latest information on College publications is available on the Internet at www.rcpsych.ac.uk 